\title{
Experiência e subjetivação política nas ocupações estudantis no Rio Grande do Sul
} LUÍS ANTONIO GROPPO ${ }^{I}$ e RodRIGO MANOEL DIAS DA SILVA II

\begin{abstract}
Eu posso falar sobre política, eu sou nova, mas eu posso. Porque o que acontece hoje, me afeta depois. Vai afetar também quem está vindo atrás e quem está aí hoje. Então, entender isso foi muito importante. Essa capacidade que a gente desenvolveu lá, de fala. [...] Antes, a gente não se entendia assim. A ocupação nos trouxe isso. Trouxe-nos essa autoestima, de dizer que a gente fez algo grande e temos capacidade de desenvolver coisas maiores ainda.
\end{abstract}

(Helena, ocupa de escola de Caxias do Sul).

\section{Introdução}

1

S OCUPAÇÕES estudantis em 2015 e 2016, no Brasil, constituíram um movimento de grande impacto, capaz inclusive de uma contenção mais ou menos bem-sucedida de políticas neoliberais que têm ameaçado os direitos sociais. Este artigo tem como objetivo analisar as formas de apropriação da experiência de ocupar com base no caso das ocupações de escolas públicas no Rio Grande do Sul (RS) em maio e junho de 2016. Essas ações coletivas inseriram-se no conjunto de manifestações contra políticas estaduais de educação e greves no serviço público estadual. Estima-se que foram ocupadas 158 escolas no RS.

Do ponto de vista teórico, buscamos cotejar o conceito de experiência segundo E. P. Thompson (pensado para a história social) e o conceito de subjetivação política segundo J. Rancière (de cunho filosófico). Como metodologia, o artigo fez uso de revisão bibliográfica e, principalmente, entrevistas semiestruturadas aplicadas a quatro jovens que participaram dessas ocupações.

Este artigo traz alguns dos primeiros resultados da pesquisa "Ocupações secundaristas no Brasil em 2015 e 2016: formação e autoformação das e dos ocupas", ' mais especificamente, aqueles elaborados pela Equipe do RS ao lado do coordenador da pesquisa.

As ocupações no Rio Grande do Sul em 2016

Em pesquisa bibliográfica sobre as ocupações estudantis no Brasil em 2015 e 2016, encontramos 14 produtos acadêmicos que tratam das ocupações no RS. Esses trabalhos contribuem para reconstruir a história das ocupações gaúchas 
em 2016, bem como para compreender as relações tensas entre os dois campos políticos que se formaram nas escolas ocupadas.

Em 2015, José Ivo Sartori (Movimento Democrático Brasileiro - MDB) assumiu o governo do Estado defendendo posturas rígidas de ajuste fiscal, por meio da redução nos recursos repassados à área social, especialmente a educação. Entre as ações, a proposição de um programa de privatizações, a extinção de secretarias e fundações e o parcelamento do salário do funcionalismo público (Severo; Segundo, 2017). Houve um sucateamento das escolas estaduais, com infraestrutura deficiente, reincidentes ausências de docentes, problemas com a merenda e o transporte escolar (Ferreira, 2017; Coelho, 2019).

Em 13 de maio de 2016, o Centro dos Professores do Estado do Rio Grande do Sul - Sindicato dos Trabalhadores em Educação (CPERS), reunido em assembleia, deflagra greve do magistério. Contudo, dois dias antes, a primeira escola gaúcha já tinha sido ocupada por estudantes. As principais pautas e reivindicações do movimento puseram em evidência a precarização das escolas, assim como a resistência ao processo político vigente no Estado, ao contrariar o Projeto de Lei (PL) n.44/2016 (que visava transferir a administração escolar a Organizações Sociais - OS) e o PL n.190/2015 (baseado na proposta do Movimento Escola Sem Partido).

O movimento de ocupação no RS foi estimulado e em parte organizado pelas entidades estudantis. Em reunião em 2 de maio, com representantes de grêmios da Região Metropolitana de Porto Alegre, elas discutiram e incentivaram a ocupação de escolas. Eram essas entidades a União Brasileira dos Estudantes Secundaristas (Ubes) - hegemonizada pela União da Juventude Socialista (UJS), ligada ao Partido Comunista do Brasil (PCdoB) - e a União Gaúcha dos Estudantes Secundaristas (Uges) - essa ligada ao Partido Pátria Livre (PPL). Elas formavam o campo democrático-popular do movimento das ocupações, ao lado da União Metropolitana dos Estudantes Secundários de Porto Alegre (Umespa) e de algumas organizações de juventude ligadas a partidos de esquerda, como o Juntos! - vinculado ao Partido Socialismo e Liberdade (Psol). (Medeiros; Januário; Melo, 2019; Coelho, 2019).

A segunda ocupação, em 13 de maio, também é na capital, mas ela se coloca como autônoma em relação às entidades estudantis. Vai, ao lado de outras escolas de Porto Alegre, formar o Comando de Escolas Independentes (CEI). O CEI representa no RS o campo autonomista (Medeiros; Januário; Melo, 2019). Em alguns atos públicos, ficariam notórias a rivalidade e a tensão entre esses dois campos, uma das marcas do movimento no RS.

O movimento das ocupações se espalha de modo acelerado pelo estado, uma vez que em 19 de maio eram 94 escolas em 39 municípios (Ratto; Grespan; Hadler, 2017). Estima-se que o movimento tenha ocorrido em 158 escolas, com intensidade distinta, e com tendência à interiorização, inclusive em municípios não acostumados com mobilizações sociais (Vianna; Viegas, 2019). Mas 
também foi forte na capital, envolvendo $57 \%$ das escolas públicas de Ensino Médio (41 escolas) (Costa; Santos, 2017). A literatura evidencia que, em várias escolas, houve apoio mútuo entre ocupas e docentes em greve, e em algumas escolas a paralisação completa das aulas só foi possível com a ocupação estudantil (Severo; Segundo, 2017).

Houve um processo institucionalizado de mediação e negociação com ocupas, em boa medida provocada pelo Poder Judiciário. O Poder Executivo gaúcho mantinha-se em postura reticente, desqualificando e reprimindo o movimento. Um grupo de estudantes, ligado às entidades estudantis, ocupa o saguão da Assembleia Legislativa do RS, pleiteando uma reunião com a diretoria da casa. Houve corte de água e ameaça de repressão policial. Após, foi iniciada "[...] uma sequência de negociações, resultando em um acordo coletivo em 14 de junho de 2016", que não foi aceito pelo CEI (Costa; Santos, 2017, p.67).

Estudantes do CEI, em 15 de junho, ocupam o prédio da Secretaria Estadual da Fazenda. A reação do governo foi mais truculenta agora. A Brigada Militar (BM) cerca o prédio e o desocupa com muita violência. Pessoas com mais de 18 anos foram presas e, mesmo liberadas, foram processadas.

Apesar das violências contra o movimento, ao lado da imagem negativa criada pela mídia, ele teve vitórias parciais, como o adiamento da votação dos PL n.44/2016, a retirada do PL n.190/2015 e a promessa da liberação do repasse de verbas e salários - segundo as entrevistas, ainda que com atraso, ao menos parte do repasse aconteceu.

\section{Experiência e subjetivação política}

Lúcia R. de Castro, a partir da psicologia social e no encontro com a obra de Rancière, nos apresentou originalmente a noção de subjetivação política, para analisar a constituição das subjetividades juvenis a partir da vivência de experiências culturais e políticas singulares (Castro, 2009; Castro; Matos, 2009). Sua ênfase são os dispositivos que jovens criam ou mobilizam para a construção de seu "eu" e de suas relações com a sociedade e o mundo político. Não se trata, portanto, de mera imposição unidirecional, por pessoas adultas, de valores e padrões estabelecidos. São reconhecidos como importantes e necessários, e não patológicos, tensões e conflitos nesses processos, bem como espaços não convencionais de participação política, incluindo a arte e a cultura.

Também, nas primeiras etapas da pesquisa, foi muito importante o reencontro com a noção de experiência do historiador marxista britânico E. P. Thompson (2002). Ela vinha sendo utilizada no campo da educação para analisar, por exemplo, a formação política por movimentos sociais (Martins, 2014) e, mais recentemente, para o próprio movimento das ocupações (Borges; Silva, 2019; Martins, 2018; Silveira, 2019). Nesses trabalhos, a ocupação é descrita como um movimento composto majoritariamente por adolescentes filhas e filhos das classes populares, em que foi mobilizada e transformada parte da cul- 
tura e das práticas sociais das classes populares, ou seja, a experiência "vivida" dessas classes emergiu como experiência "modificada" na ação coletiva.

A experiência de classe "modificada" vai ao encontro da noção de subjetivação política de Rancière, para a compreensão de vivências políticas contestadoras, inesperadas ou contingentes e que rompem o cotidiano determinado. Rancière parece radicalizar a ideia da experiência como "auto-fazer-se" de uma classe social (Thompson, 1987). A construção de sujeitos políticos se dá por meio do dissenso, ou seja, como ruptura da ordem social e política dada (Rancière, 1996). O dissenso abala as fronteiras estabelecidas na comunidade política entre quem tem o direito à palavra e quem não o tem. É um abalo na partilha do sensível ou uma fissura no modo como a ordem social distribui de modo desigual os lugares e as funções às pessoas (Ranciàre, 2014)

A subjetivação política é sobretudo um processo de desidentificação, que rompe ou abala as funções sociais esperadas de quem, na normalidade da "ordem policial", associava sua função social a um status desigual no corpo social (Rancière, 2014). Nas ocupações, trata-se da possibilidade de ruptura em relação às funções e o status de adolescente e aluna e aluno. Para Vianna e Viegas $(2019$, p.220), as práticas educativas das ocupações "possibilitaram também a desmistificação de estereótipos sobre a juventude”, e, para tanto, fazem a seguinte citação:

Aluno-porteiro, aluno-merendeiro, aluno-faxineiro, aluno-diretor, aluno-inspetor. A desenraização total do sujeito aluno, do seu lugar fixo de representação em nome de uma subjetividade aluno, que se constitui a partir do engajamento em atividades normalmente apartadas do processo de formação pedagógico. (Pais; Pipano apud Vianna; Viegas, 2019, p.221)

Trata-se da desidentificação em relação à função social de estudante - parte do processo de subjetivação política dessas pessoas que vieram a se chamar como ocupas. Na verdade, também da condição tradicional da mulher, considerando a proeminência das ocupas no movimento: como disseram Pinheiro-Machado e Scalco (2018), as "vedetes" dos rolezinhos de 2014 se tornaram as ocupas de 2015 e 2016, vivenciando um feminismo secundarista, adolescente e periférico impactante.

Mas a subjetivação política como desidentificação pode construir sujeitos coletivos, ainda que provisórios, não apenas pelo deslocamento de uma identidade social. Ou melhor, justamente pelo deslocamento de seu sentido, uma identidade social marginalizada pode vir a se tornar um potencial denominador comum de todas as pessoas, revelando que, do ponto de vista político, todas são fundamentalmente iguais. Isso pode explicar a relativa heterogeneidade social das e dos ocupas, que não se resumem a estudantes da escola ocupada, já que lá estiveram também estudantes de outras escolas ou que haviam evadido, assim como algumas pessoas adultas, como mães de ocupas e militantes. 


\section{Os sujeitos e as ocupações}

Em maio e junho de 2019, foram feitas quatro entrevistas com ocupas do RS. As pessoas entrevistadas escolheram seus pseudônimos. Nas entrevistas, as experiências de participação na ocupação convergem em alguns aspectos, mas se diferenciam em outros, graças à diferentes formas de participação e às diferentes dinâmicas da ocupação, em especial por causa do local onde ficavam a escola (capital ou interior, centro ou periferia).

Ana Paula era militante do Juntos! - onde continua atuando - e membro do Grêmio, que organizou e coordenou politicamente a ocupação de sua escola, na região central de Porto Alegre. Branca, lésbica, umbandista e com renda familiar de 3,5 salários mínimos, tinha 18 anos quando ocupou. Ela atuou intensamente durante os dois meses do movimento no RS, envolvendo-se na preparação das ocupações no estado desde as primeiras assembleias gerais convocadas pelas entidades estudantis. Também foi uma ocupante da Assembleia Legislativa.

Uma assembleia na escola de Ana Paula, ocorrida após a exibição de um documentário sobre as ocupações paulistas, aprovou a ocupação. Iniciaram a ocupação em um domingo, logrando a direção e o guarda da escola, que achavam que ia acontecer uma atividade formativa do Grêmio. Era a quarta escola a ser ocupada no RS, chamando forte atenção da mídia. Ela demonstra grande clareza sobre as pautas, que combinavam temas mais gerais e problemas específicos de cada escola ocupada. Seu relato valoriza os impactos de mais largo prazo da ação:

Aquilo foi muito maior do que parece ser. Foi muito mais do que barrar uma reforma. Foi muito mais do que conseguir um ginásio de qualidade. Foi muito mais do que ter um quadro de professores. Eu acho que a gente conseguiu mostrar que a gente pode transformar as coisas, $[\ldots]$ que a gente pode ir junto pensando e mudando a sociedade [...]. Hoje, tem muitas pessoas que estavam na escola que eu encontro na universidade, e se eu perguntasse antes da ocupação, não saberiam dizer o que é uma universidade pública. Foi um espaço político muito importante. (Ana Paula)

Daniel ocupou escola central de Porto Alegre quando tinha 16 anos. Declara-se negro, heterossexual, de religião de matriz africana e com renda mensal familiar de 3,5 salários mínimos. Era militante do coletivo juvenil Vamos à Luta (ligado ao Psol, partido ao qual hoje é filiado). A escola da capital que Daniel ocupou foi importante aglutinador do CEI. A ocupação, à qual ele veio participar depois de iniciada, foi organizada e coordenada pelo Grêmio da escola, composto apenas por mulheres. As tarefas de Daniel foram sobretudo políticas: o diálogo com outras escolas e a "construção de um campo político dentro do próprio comando de ocupações". Seu relato indica o quanto as e os ocupas de sua escola desconfiavam das entidades estudantis e dos partidos políticos, com os quais acabaram por estabelecer relações bastante complexas, na tentativa de 
preservar a autonomia da ocupação: "A gente fez com que a escola fosse nossa por aquele curto período de tempo". A motivação que o levou a ocupar era política, mas também pessoal, somada ao desejo de evitar mais precarização do ensino público:

Eu achava que as coisas, da maneira que estavam, não podiam ficar. [...] a gente teve talvez o pior governo da história do RS. [... Sempre fui um defensor irrestrito, irremediável, do pensamento livre dentro das escolas. [...] o que me motivou na verdade foi sentir na pele o que muitos estudantes sentiam há muito tempo. Então, eu acho que foi a coragem daquele grupo de pessoas $[. .$.$] . A gente não conseguiu avançar, mas a gente conseguiu$ fazer com que a escola não fosse mais precarizada. (Daniel)

Mayna ocupou escola em bairro central de Canoas, município da Região Metropolitana de Porto Alegre. Tinha 16 anos durante a ocupação, declara-se negra, bissexual, umbandista e com renda familiar de 1 salário mínimo. Trabalha em serviços eventuais, como manicure e babá. Era independente - sem filiação a organizações relacionadas a partidos políticos. Cerca de 15 estudantes independentes, incluindo ela, organizaram a ocupação, inclusive como reação a estudantes da Ubes que teriam iniciado a mobilização em sua escola: "A gente disse: [...] 'a gente não quer nada partidário'”. Além de sua escola, participou da ocupação de outra escola em bairro periférico: "Eu intercalava, um pouco em uma e um pouco em outra”. Em sua escola, na verdade, as aulas já estavam suspensas pela adesão de docentes à greve, mas, ainda assim, parte de estudantes dessa escola chegou a organizar um protesto contra a ocupação.

O que motivou Mayna foi a preocupação com o futuro de filha ou filho que viesse a ter, que certamente estudaria em escola pública. Participou das ocupações durante os seus dois meses de duração. Sua principal tarefa era a alimentação. Antes de afirmar que, em suas pautas gerais, o movimento não foi totalmente vitorioso, considerou que a ocupação de sua escola "teve um resultado muito bom”, graça à liberação de verbas: “Hoje eu vejo fotos da escola e eu olho para uma escola pintada, eu olho para um pátio bem arrumado e penso: 'Bah, outras pessoas estão utilizando do bem que eu fiz, que nós todos fizemos'”. Durante a ocupação, o grêmio estudantil foi recriado.

Helena ocupou escola em Caxias do Sul, segundo município mais populoso do RS, quando tinha 16 anos. Declara-se branca, heterossexual, católica não praticante e com renda familiar de 10 salários mínimos - destoando da maioria de colegas de sua escola, assim como das demais pessoas entrevistadas, que tinham renda mais baixa. Sua principal motivação foi uma pauta interna: o afastamento da diretora, que seria muito autoritária ("a porta dela estava sempre fechada”). Atuou especialmente na comunicação e integração entre as escolas ocupadas em seu município. Distintamente de outra ocupação central, orientada pelas entidades estudantis, sua escola buscou garantir o caráter não partidário e independente da ocupação, pelo medo de manipulação e o desejo de autono- 
mia. A escola de Helena enfrentou ao menos duas tentativas de invasão por um grupo formado por pais e outros membros da comunidade. Para se defender, ocupas contaram com o apoio de um "bloco de lutas", agora formado por pais e mães e outras pessoas adultas que apoiavam a ação coletiva. Em uma dessas tentativas, invasores arrebentaram uma porta da escola e quebraram a mão de um ocupa.

A dinâmica das ocupações girou fundamentalmente em torno de atividades políticas e atividades formativas, que, em boa parte do tempo, se fundiram ou pouco se distinguiram entre si. Ao fazer política, se aprendia a fazer política. Por exemplo: as assembleias que decidiam pela ocupação muitas vezes eram precedidas por palestras sobre os projetos de lei e a precarização do ensino, ou vídeos sobre a ocupação paulista; nas oficinas, o estudo desses projetos de lei, das legislações e das instituições políticas representativas continuava, fornecendo insumos para a luta; foram elaboradas versões próprias da cartilha no RS - Ana Paula participou da construção de uma delas, destinada especialmente às escolas do interior, que "não tinham tanto engajamento político ou que ainda estavam iniciando e não sabiam como fazer”.

Ao fazer política, as e os ocupas também ensinavam novas formas de organização e de ensino-aprendizagem. Por exemplo: não apenas enfatizavam a autonomia das e dos ocupas, mas também a horizontalidade das assembleias e da distribuição das tarefas pelas comissões; as oficinas e atividades culturais promoviam tanto um currículo alternativo, quanto componentes curriculares previstos, mas não cumpridos. tratando sobre relações de gênero, cultura e história afro-brasileira e a própria formação política.

Escolas centrais das capitais e em bairros de classe média tenderam a receber mais ajuda de militantes e pessoas adultas apoiadoras, não apenas alimentos, agasalhos e orientação jurídica, mas também oficinas e palestras. Em contrapartida, a bibliografia, assim como a entrevista de Mayna, tem mostrado que a ajuda externa era oferecida mais para as escolas centrais ou de bairros não periféricos. O relato de Mayna trata, sobretudo, de duas ocupações em Canoas que lutavam para sobreviver, com pouquíssima ajuda externa, tanto para a estrutura básica quanto para as atividades formativas.

Os relatos sobre as atividades formativas trazem não apenas uma forte preocupação com os conteúdos delas, mas também com a sua forma, com os “métodos educacionais". Essas atividades, muitas vezes, tinham lugar em espaços alternativos à sala de aula, como a quadra, o ginásio e os laboratórios, e usavam dinâmicas diferenciadas. $\mathrm{O}$ símbolo desta dinâmica educacional foi o círculo ou a roda. Segundo Daniel, antes de desocuparem a escola, organizaram todas as salas com as carteiras em círculo:

A gente organizou a sala da maneira que a gente gostaria $[\ldots]$, com círculos, com o professor sendo mais um agente, sendo um facilitador de nosso aprendizado. Então, no primeiro momento começamos a discutir os cortes 
da educação, a precarização da escola, a precarização do ensino e a escola sem partido, e depois discutimos um novo modelo de escola, a escola que a gente queria. (Daniel)

O círculo como experiência educacional - cuja tradição remonta ao menos os Círculos de Cultura de Paulo Freire (1985) - materializa a experiência da igualdade política naquele momento de dissenso. O círculo permite que as pessoas olhem umas às outras nos olhos; ele torna a educadora e o educador alguém que facilita o aprendizado, em vez de guiar educandas e educandos de modo superior. Ele também é uma mensagem para que a escola mantenha algo daquela igualdade política que a ocupação viveu.

\section{Experiência e subjetivação política nas ocupações}

Apesar das limitações estruturais vividas na escola de Mayna, também ela pode viver ao menos em parte a práxis democrática radical do movimento das ocupações, assim como o feminismo secundarista e popular. Entretanto, as dinâmicas particulares de cada ocupação podem ter facilitado ou dificultado essa vivência da democracia radical e dos valores feministas. Por exemplo, na escola central da capital gaúcha, que Ana Paula ocupou, o exercício da paridade de gênero parece ter sido muito natural, tal qual um adendo de seu registro sobre as comissões:

A gente também tentou fazer as nossas comissões igualar as questões de gênero, porque a gente achava ruim que os meninos ficassem na segurança $\mathrm{e}$ as meninas ficassem cozinhando. Tinha que ser pelo menos meio a meio. $\mathrm{Na}$ nossa escola foi algo muito importante, as meninas não participaram da questão da cozinha. (Ana Paula, Porto Alegre)

Já na escola de Helena, em Caxias do Sul, a incorporação de valores feministas foi uma construção mais árdua. Essa escola, ainda que não situada na periferia, recebia estudantes, sobretudo, das classes populares. Valores tradicionais masculinos ligados à "valentia" e agressividade foram trazidos pelos meninos que queriam cuidar da comissão de segurança. Em seu relato, Helena traz o seu esforço para compreender o ponto de vista e a história daqueles meninos, assim como registra uma paulatina desconstrução do machismo deles:

Eram meninos que desenvolveram essa postura de corajoso, de protetor, porque tinham que proteger irmãos, brigar por coisas, e às vezes eram de bairros mais violentos. [...] Eles pensavam que ali na ocupação eles também iam dar a palavra final. [...] E vendo a gente, meninas, como protagonistas de discussões e debates, talvez isso assustasse eles um pouco. Mas depois da ocupação, esses comportamentos deles foram muito melhorados. [...]. A ocupação [...] foi um choque de realidade para todo mundo, de dialogar, de entender, de se ver como pessoa política. [...]A ocupação nos possibilitou construir esse respeito pelo outro, que ainda tem que ser muito desenvolvido, mas foi algo eu que eles fizeram em um curto período de tempo. (Helena) 
Esses relatos indicam que as ocupações possibilitaram importantes processos de subjetivação política, com a ressalva de que eles se deram em graus e amplitudes diversas, pois, como dito, as próprias escolas, as dinâmicas da ação coletiva, as formas de participação e os contextos eram heterogêneos. Esses processos de subjetivação política como desidentificação apareceram menos em Mayna - nem mesmo sua orientação bissexual foi atribuída à experiência de ocupa -, provavelmente pelos limites das ocupações que participou e da sua própria forma de participação. Mas apareceram com mais força nos demais relatos, inclusive na escola dos meninos periféricos de Caxias do Sul. Segundo Daniel:

Naquele momento, dentro da ocupação, os alunos que eram tachados, marginalizados pela própria direção, alunos que, na visão dela, vinham para ficar só no cantinho fumando maconha, que não faziam nada, tomaram para si a escola e mostraram que o problema não estava neles. O problema estava no modelo de educação que estava estabelecido na nossa sociedade. Inclusive, é um modelo de educação bem antigo, que tem que ser mudado. [...] o mais gratificante na ocupação foi o fato de que os alunos tomarem para si o espaço que é seu por direito. (Daniel)

Se o relato de Daniel destaca a ruptura com a posição social marginal ou excluída atribuída às alunas e aos alunos, o relato de Helena, a seguir, ao criticar a visão que a burocracia governamental e pessoas contrárias ao movimento tinham sobre as e os ocupas, parece balizar a hipótese de que houve uma desidentificação em relação à condição adolescente, tradicionalmente tida como uma cidadania pela metade, como uma fase da vida em que não seria possível ser sujeito político relevante (Borges; Silva, 2019). Essa condição adolescente foi atribuída de modo tão pungente então, que associou ocupas à outra categoria etária ainda mais inferior no imaginário social - a infância:

Eles tratavam a gente de formas desrespeitosas, porque eles enxergavam a gente como crianças que estavam indo na onda, que não tinham noção do que estavam fazendo. Mas a gente tinha a noção, a gente estava aprendendo lá dentro. $[\ldots]$ a gente tinha capacidade de construir esse movimento. (Helena)

A experiência da ocupação teve grande impacto subjetivo sobre as e os ocupas. Ela suscitou intensos aprendizados políticos e processos de transformação de si. Como se viu, a subjetivação política se deu durante a ação coletiva que, por meio da desidentificação em relação a papeis heterônomos e subalternos, constituiu, com diferentes graus de efetividade, um coletivo de pessoas que se viam e agiam como iguais, a despeito de sua diversidade de condições e papéis sociais prévios.

Ana Paula, em seu relato, permite-nos reafirmar a hipótese de que um processo de transformação de si, que foi engendrado por essa experiência, guarda, ao menos em latência, novas jornadas de assunção como sujeitos políticos:

A gente conseguiu colocar as nossas ideias $[\ldots]$ e que a gente poderia tam- 
bém, apesar das nossas diferenças, construir coisas juntos. [...] Eu acho que a gente entrou com uma cabeça, mas eu acho que todo mundo saiu muito diferente. Cada um teve alguma coisa que pessoalmente teve mais impacto. [...] Eu acho que a gente entendeu um pouco o nosso papel nas coisas e como que a gente faz isso. (Ana Paula)

Daniel destaca o quanto as pessoas puderam conhecer melhor a si mesmas e à sua situação educacional e social:

Acho que as pessoas começaram a entender as coisas de outra forma após as ocupações. Entenderam o modelo de escola que a gente tinha, entenderam as contradições do dia-a-dia pelas quais nós passávamos. Inclusive, a gente tem relatos de estudantes negros que eram abordados todos os dias pela Brigada Militar. A gente tem relato de estudantes que eram, mas não se entendiam como LGBTT, e que depois disso, depois das discussões que nós fizemos dentro da escola, se descobriram. Acho que a gente foi a faísca, para cada pessoa, de algo que é muito maior. Acho que também a gente incentivou muito o pensamento crítico, colocou que $[\ldots]$ a sociedade, da maneira que está organizada, não nos serve. (Daniel)

Helena, no relato a seguir, parece afirmar sua assunção como sujeito político, vivida de modo intenso no tempo curto mas concentrado da política como dissenso, que, por isso, pareceu uma "eternidade":

Eu posso estar aqui, eu posso falar. Eu sou jovem, mas eu posso, não é só vocês, velhos, ou homens de terno que podem decidir as coisas. A gente vive, a gente pode opinar sobre as nossas realidades e também escutar sobre as dos outros. Eu acho que isso foi o que a ocupação nos trouxe. Pessoas mais preparadas para vida, para falar, para ouvir também, que é superimportante. [...] Essa é a maior vitória que eu enxergo. Com todos esses processos que a gente teve lá dentro neste curto período de tempo, que para nós, na verdade, foi uma eternidade, a gente teve um crescimento muito rápido dentro da ocupação. [...] É algo que a gente vai levar para a nossa vida inteira essa experiência. Isso é uma coisa única. (Helena)

Mesmo Mayna, apesar das limitações estruturais das ocupações em que atuou, e da sua própria forma de participação, nos dá um indício de que também sua experiência foi um processo de subjetivação política. É quando ela afirma que sua motivação para ocupar foi a preocupação com o futuro da escola pública para a filha ou filho que um diria poderia ter. Ela, assim, vai ao encontro do relato de Helena na epígrafe do artigo: "Eu posso falar sobre política, eu sou nova, mas eu posso". Há um deslocamento do sentido de adolescência e juventude: em vez do “desenvolvimento" e da "transição" à idade adulta significarem imaturidade e, portanto, incapacidade de participação política plena, passam a justificar, no discurso das ocupas, o direito ao seu reconhecimento como sujeitos políticos, para que possam participar das decisões presentes que implicarão o seu futuro. A juventude, de categoria etária, ou justamente pelo deslocamento do sentido usual de categoria etária, se torna uma categoria política no discurso e prática dessas ocupas. 
Mas as marcas deixadas pela experiência da ocupação não foram em sua totalidade positivas - para a própria Helena, vivências negativas, somadas a outros problemas pessoais, a levaram a uma depressão. Todas as entrevistas trazem relatos de ameaças, agressões e movimentos de desocupação, e algumas citam, após a desocupação, ambiente escolar hostil e perseguições.

Daniel relatou sobre o frio e o medo de perseguição e invasão, afora a desconfiança da própria direção:

Era um medo de muitas vezes sair na rua, era o medo de alguém invadir a ocupação, era o medo da própria polícia. Enfim, a gente sabia que o confronto das ocupações não era um confronto contra a Secretaria de Educação apenas. Era um confronto diretamente com o governo do Sartori e com o aparato estatal. [...] Havia muita perseguição, tinha medo da própria direção de dedurar, de entregar os estudantes que estavam ali na ocupação. (Daniel)

Mayna lamenta que a maioria das e dos estudantes de sua escola não entenderam os motivos da ocupação, havendo até mesmo um protesto de parte de discentes contra o movimento. Sua maior frustração foi "ver aluno fazendo protesto contra $[. .$.$] . A gente tá ali reformando a escola deles, dando um up e$ eles fazendo protesto. Sei lá, gente mimada, não sei o que passa na cabeça. Foi bem frustrante ver aquela cena, toda aquela gente indo contra". Ana Paula diz que havia muito medo "de tudo o que poderia acontecer", em especial por conta da grande exposição negativa pelas mídias comerciais e nas redes sociais, com muitas ameaças e violências, como carro rodando a escola durante a noite, buzinando, e pessoas atirando pedras na escola. Ela, ao lado de outras meninas do Grêmio, chegou a ser agredida por estudantes do Ensino Técnico noturno, atiçados por uma professora que quebrou com uma pedra uma porta da escola para a invadir.

Processos de subjetivação política como desidentificação e assunção de si como sujeito político foram, para as pessoas entrevistadas, a forma como absorveram a experiência da ocupação. Processos intensos que significaram maior consciência de si, sobre a política e a sociedade, mas também sofrimento e dor.

\section{Após a ocupação}

Após o movimento, quando aqueles coletivos fugazes se desmancham, restam parcas tentativas de encontros mensais, uma mais efetiva criação de amizades relativamente duradouras e, como se demostrou acima, indivíduos que guardam na memória, no corpo e na mente marcas daquela vivência.

Restam também esperanças e expectativas de novas mobilizações políticas e ações coletivas, como em Ana Paula, que afirma que várias das pessoas que estiveram com ela na ocupação estão na universidade, e com outras mantém vínculo pelas redes sociais. Em contrapartida, Daniel se diz frustrado por causa de ocupas que não conseguiram continuar participando politicamente de modo ativo:

[...] Acho que a vida é muito injusta nesse sentido. Tem pessoas que são 
muito boas do ponto de vista militante, do ponto de vista até crítico mesmo. [...] E hoje eu vejo pessoas, que foram ganhas para um projeto de vida mesmo, que, ou têm que trabalhar, ou trabalham ou estudam, e que não podem dedicar o tempo delas para construção de um novo modelo de sociedade. (Daniel)

Após a ocupação, Helena chegou a participar de alguns atos públicos, teve vários convites de juventudes partidárias e tentou formar um grupo de estudos em sua escola sobre o anarquismo:

Mas depois da ocupação eu acho que eu entrei em uma depressão... Porque eu fui muito pública. As minhas falas ficaram supermarcadas, tinha vídeo meu por tudo e tinha gente falando de mim. E eu não gostava disso. E eu fiquei mais reclusa. Comecei a ter medo de me expor de novo [...] e eu acabei me retraindo muito. Eu era convidada a ir a lugares e eu não ia. [...] eu não dava mais rolê. Eu não via mais os meus amigos. Foi bem difícil essa fase. [...]. Foi por isso que eu não participei de mais nada. (Helena)

Ana Paula, Daniel e Helena tiveram trajetórias escolares mais lineares, completando o Ensino Médio regularmente e logo ingressando na educação superior em universidades federais. Diversamente, Mayna registra um truncado final do Ensino Médio e a dificuldade de ingressar na educação superior. Ela também foi a que menos conseguiu se envolver em atividades políticas após a ocupação. Contudo, deseja cursar Serviço Social, projeto bastante influenciado pela ocupação, e diz ter grande admiração por ocupas que hoje estão na educação superior: "Logo, logo, vai ser eu" - e espera reencontrar elas e eles na universidade.

\section{Considerações finais}

A experiência da ocupação marcou fortemente os quatro relatos, que tenderam a considerá-la como um divisor de águas nas suas trajetórias. Certamente, há peso e angústia, como explicita o caso de Helena, acometida de depressão após a ocupação. Ainda aí, entretanto, a pesquisa tem conhecido o grande impacto subjetivo e na trajetória de vida sentido por adolescentes que participaram de ações coletivas. A pesquisa pode, inclusive, em outro momento, avaliar o quanto essa experiência se aproxima ou não das vivências de pessoas em outras categorias etárias nos movimentos sociais, sempre considerando a maneira como a idade se articula a outros fatores, como classe social, gênero, raça e politização.

$\mathrm{O}$ que temos, até o momento, é que, para as e os adolescentes, a experiência da ocupação foi uma vivência transformada das relações educacionais e políticas. Oportunizou processos de subjetivação política que significaram também processos de desidentificação em relação aos papéis sociais previamente formulados de estudante (aprendiz passivo) e adolescente (com pouca capacidade de ação política). As memórias da ocupação, nos relatos, dão relevo à ruptura, a inovação e à descoberta, tanto nas dinâmicas cotidianas e escolares, quanto na própria forma de conceber a política. 
Entretanto, quando as pessoas entrevistadas tratam de suas trajetórias políticas, se percebe que o envolvimento prévio com alguma organização política, em especial juventudes de partidos de esquerda, facilitou a continuidade da participação, ainda que todos os relatos indiquem uma grande disposição de se engajar em novas lutas sociais progressistas. Nas trajetórias escolares, a ocupação contribuiu para a decisão de ingressar em um curso superior e mesmo para definir o curso e a carreira profissional que se desejava seguir - essa decisão, em todos os casos, guarda forte relação com a posição política e a visão de mundo criadas ou reforçadas com a experiência da ocupação.

As ocupações secundaristas foram largamente protagonizadas por pessoas, como Mayna, sem nenhuma vivência como militantes, ativistas ou simpatizantes de organização política ou, como Helena, com muito pouca. Ao mesmo tempo, o cotejo de relatos entre, de um lado, ocupas com relevante experiência organizativa (como Ana Paula e Daniel) e, de outro, com pouca ou nenhuma, tem mostrado, novamente, a importância das vivências políticas prévias, mesmo quando se tratam de adolescentes. Ao menos no curto prazo, essas vivências, ao lado da influência da família e até da escola, foram decisivas na maneira como a subjetivação política experienciada na ocupação impactou na trajetória política desses sujeitos.

Apesar de as quatro pessoas entrevistadas demostrarem que se mantiveram no campo político da esquerda ou progressista, apenas quem pertencia a uma organização, ou seja, quem militava antes e durante a ocupação, casos de Ana Paula e Daniel, continuaram a ter relevante atuação política. É claro, não se deve esquecer as dramáticas alterações no contexto político brasileiro recente, que assistiu o acirramento político-ideológico, a conjuntura desfavorável à atuação de independentes e as vitórias eleitorais da extrema direita. As independentes Helena e Mayna, ao menos até agora, não encontraram condições para dar continuidade à participação política, ou seja, para converter a memória e a experiência de um tempo de intensa subjetivação política em uma atuação contínua e destacada no espaço público ou no cotidiano.

Mayna e Helena, ambas independentes, também coincidem em outros pontos, como sua condição adolescente, estudantil e feminina. Entretanto, Mayna contrasta com Helena em outros elementos muito relevantes: de família pobre, com trabalhos eventuais e mal pagos, estudando em escolas periféricas e precárias, com dificuldade de completar o Ensino Médio e de acessar à educação superior pública. Mayna, apesar de todo esse porém, foi uma ocupa. E, ainda mais importante, parece representar o gênero, a condição social e a vivência política de parte importante das e dos ocupas, talvez da sua maioria. Ela representa aquelas e aqueles que nem sempre têm sido fácil localizar para as entrevistas, cujos nomes não ficaram registrados na mídia e às vezes nem mesmo nas páginas das ocupações nas redes sociais, que interessaram menos às organizações políticas e redes de apoio das classes médias e altas, que para as escolas periféricas pouco doaram alimentos, cobertores e oficinas. 
Menos difícil tem sido contatar ocupas como Ana Paula e Daniel, militantes e de escolas centrais e da capital, inclusive porque continuam muito atuantes politicamente. Em maio de 2019, estavam lá, nos atos contra os cortes na educação superior pública, provavelmente cumprindo tarefas para as organizações que militam. Helena, dada a reclusão a qual se impôs, não participou desses atos, mas seu ânimo durante a entrevista indica que, da próxima vez, ela poderá estar presente. Já Mayna deseja reencontrar amigas e amigos das ocupações na universidade pública, quando realizar o projeto de ingressar no curso de Serviço Social. São indícios de que a experiência da ocupação se reverteu, para militantes, em uma continuidade da ação política, assim como na construção e na consecução de um projeto educacional (a universidade pública). Para independentes, que foram a maioria das e dos ocupas, a subjetivação política vivida tem um impacto mais descontínuo, mas de grande latência, de enorme potencial. O médio e longo prazo talvez comprovem isso, com novas ações coletivas nas quais venham se juntar, novamente, Ana Paula e Daniel com a independente Helena e a persistente Mayna.

Agradecimentos - A Tainah Motta Nascimento, Scarlett Giovana Borges e Amanda Franciele Garcia, membros da equipe RS, pela realização das entrevistas e das transcrições.

A Marilia Spósito, pelos comentários à primeira versão do texto.

Nota

1 A pesquisa é financiada pelo Conselho Nacional de Desenvolvimento Científico e Tecnológico (CNPq) para ser desenvolvida entre 2019 e 2021, apoiada por uma equipe nacional que tem envolvido 12 IES.

\section{Referências}

BORGES, S. G.; SILVA, R. M. D. Condição adolescente e socialização política nas ocupações secundaristas em Caxias do Sul, RS. Práxis Educativa, v.14, n.3, p.1-17, 2019.

CASTRO, L. R. Juventude e socialização política: atualizando o debate. Psicologia: Teoria e Pesquisas, v.25, n.4, p.479-87, 2009.

CASTRO, L. R.; MATTOS, A. R. O que é que a política tem a ver com a transformação de si? Considerações sobre a ação política a partir da juventude. Análise Social, v.XLIV, n.193, p.793-823, 2009.

COELHO, G. O movimento das ocupações de escolas no Rio Grande do Sul: dinâmicas e tensões internas. In: MEDEIROS, J.; JANUÁRIO, A.; MELO, R. Ocupar e resistir: movimentos de ocupação de escolas pelo Brasil (2015-2016). São Paulo: Editora 34; Fapesp, 2019, cap.7, p.172-95.

COSTA, L. B.; SANTOS, M. M. Espaços virtuais dos movimentos das escolas ocupadas de Porto Alegre: o apoio mútuo como base da inteligência coletiva. ETD - Educação Temática Digital, Campinas, v.19, n.1, p.49-73, 2017. 
FERREIRA, S. R. Jovens secundaristas e o exercício democrático nas ocupações escolares em 2016 em Porto Alegre. In: REUNIÃO NACIONAL DA ANPEd, 38, 2017, São Luís, MA.

FREIRE, P. Educação como prática da liberdade. 16.ed. Rio de Janeiro: Paz e Terra, 1985.

MARTINS, S. A. E. P. O fazer político dos jovens das classes populares: as ocupações estudantis paranaenses. Revista Pedagógica, Chapecó/SC, v. 20, n. 43, p. 143-167, 2018 .

Thompson e a educação: a socialização como experiência. Revista HISTEBR On-line, Campinas, n, 59, p. 304-317, 2014.

MEDAETS, C.; MEZIE, N.; CARVALHO, I. C. M. "Todo desconstruidinho": jovens líderes do movimento estudantil Ocupa Tudo RS. Reflexão e Ação, Santa Cruz do Sul, v.27, n.3, p.182-201, 2019.

MEDEIROS. J.; JANUÁRIO, A.; MELO, R. Introdução. In: (Org.) Ocupar e resistir. Movimento de ocupações de escolas pelo Brasil (2015-2016). São Paulo: Editora 34, 2019. p.19-36.

PINHEIRO-MACHADO, R.; SCALCO, L. M. Da esperança ao ódio: Juventude, política e pobreza - do lulismo ao bolsonarismo. Cadernos IHU Ideias, São Leopoldo, Universidade do Vale do Rio dos Sinos, ano 16, n.278, 2018.

RANCIÈRE, J. O desentendimento: política e filosofia. São Paulo: Editora 34, 1996.

Nas margens do politico. Lisboa: KKYM, 2014.

RATTO, C. G.; GRESPAN, C. L.; HADLER, O. H. "Ocupa $1^{\circ}$ de Maio": ciberdemocracia, cuidado de si e sociabilidade na escola. ETD - Educação Temática Digital. Campinas, v.19, n.1, p.99-118, 2017.

SEVERO, R. G.; SEGUNDO, M. A. \#Ocupatudors - socialização política entre jovens estudantes nas ocupações de escolas no Rio Grande do Sul. ETD - Educação Temática Digital. Campinas, v.19, n.1, p.73-98, 2017.

SILVEIRA, I. B. "Lute como uma menina": gênero e processos de formação na experiência das ocupações secundaristas. 2019. Dissertação (Mestrado em Educação, Universidade Federal de Alfenas), Alfenas, 2019.

THOMPSON, E. P. A formação da classe operária inglesa. 4.ed. Rio de Janeiro: Paz e Terra, 1987. v.1: A árvore da liberdade.

Educação e experiência. In: Os románticos: a Inglaterra na era revolucionária, Rio de Janeiro: Civilização Brasileira, 2002. p.11-48.

VIANNA, R. B.; VIEGAS, M. F. A “má educação” nas ocupações de escolas no Brasil e no Chile. In: SILVEIRA, E. da S.; MORETTI, C. Z.; PEREIRA, M. V. (Org.) Educação clandestina. Porto Alegre: EDIPUCRS, 2019. v.1, p.203-26.

RESUMO - O tema do artigo são as formas de apropriação por adolescentes da experiência de ocupações de escolas no Rio Grande do Sul (RS) em maio e junho de 2016. Tem como objetivo compreender de que modo essa experiência se converteu em um processo de subjetivação política para tais adolescentes, com base em entrevistas semies- 
truturadas aplicadas a adolescentes que participaram dessas ocupações. Conclui-se que a experiência da ocupação permitiu processos de subjetivação política que promoveram a desidentificação em relação aos papéis sociais previamente formulados de estudante (aprendiz passivo) e adolescente (sem capacidade de pensar e agir politicamente).

PALAVRAS-CHAVE: Ocupações estudantis, Ação coletiva, Subjetivação política, Experiência, juventude.

ABSTRACT - The theme of the article are the forms of appropriation by adolescents of the experience of school occupations in Rio Grande do Sul in May and June 2016. It aims to understand how this experience became a process of political subjectification for those youths, based on semi-structured interviews applied to those who participated in the occupations. It concludes that the experience of occupation enabled processes of political subjectification that promoted the de-identification of previously formulated social roles for students (passive apprentices) and adolescents (unable to think and act politically).

KErWORDS: Student occupations, Collective action, Political subjectification, Experience, Youth.

Luis Antonio Groppo é professor da Universidade Federal de Alfenas (Unifal-MG) e pesquisador do Conselho Nacional de Desenvolvimento Científico e Tecnológico (CNPq), doutor em Ciências Sociais pela Universidade Estadual de Campinas.

@ - luis.groppo@gmail.com / https://orcid.org/0000-0002-0143-5167.

Rodrigo Manoel Dias da Silva é professor da Escola de Humanidades e do Programa de Pós-Graduação em Educação da Universidade do Vale do Rio dos Sinos (Unisinos) e líder do Grupo de Estudos e Pesquisas em Sociologia da Educação (Unisinos, CNPq). Doutor em Ciências Sociais pela Unisinos. @ - rodrigoddsilva@hotmail.com / https://orcid.org/0000-0001-8501-5903.

Recebido em 4.5.2020 e aceito em 16.6.2020.

${ }^{\text {I }}$ Universidade Federal de Alfenas, Alfenas, Minas Gerais, Brasil.

II Escola de Humanidades, Universidade do Vale do Rio dos Sinos, São Leopoldo, Rio Grande do Sul, Brasil. 